\title{
Tale: Defamiliarizing ludonarrative puzzles
}

\author{
Antonino Frazzitta and Charlie Hargood \\ Bournemouth University, UK \\ $\{$ s5117080, chargood\}@bournemouth.ac.uk
}

\begin{abstract}
Tale is a puzzle platformer game which explores a changing relationship between two characters through challenges in communication and experimentation, to loneliness and the anxiety it brings, and finally to reunification, collaboration, and growth. The game does not make use of traditional storytelling techniques such as text or dialogue, but rather employs ludonarrative design through mechanics as metaphor and defamiliarization. In this demo paper we present our design and approach to using these concepts to tell the story of our characters principally through movement and puzzles.
\end{abstract}

Keywords: Interactive Narrative $\cdot$ Ludonarrative $\cdot$ Mechanics as Metaphor · Puzzles · Game Design.

\section{Introduction}

Tale $^{1}$ is a $2.5 \mathrm{D}$ puzzle-platformer that seeks to explore and demonstrate ludonarrative design through an approach based on Mechanics as Metaphor and defamiliarization. Developed in Unity 3D Tale follows the relationship between two nameless protagonists through a ruined fantasy world across 3 levels and 9 puzzles. The puzzles include a variety of platformer mechanics designed to explore the emotional state of the protagonists and the nature of their relationship. There is no text or dialogue, the play alone delivers a tale of communication and experimentation, loneliness and anxiety, and collaboration and growth.

Ludonarrative narrative design seeks a blend of play and storytelling [1] where by the mechanics of the game themselves may reinforce, and even tell, the story through play. A common approach to this is the notion of mechanics as metaphor where by the form and interaction of a gameplay mechanic becomes a metaphor within the narrative. The earliest mention of this concept was likely Jason Rohrer in a personal essay on his work on Passage [6] where the progression from left to right and changing visuals are a metaphor for the passage of life, though numerous other designers and scholars have discussed the concept. This can be effectively paired with defamiliarization within design, a notion with its origins in formalism [8] but more recently explored within ludonarrative [5]. A design may be defamiliarized by subverting player expectations, breaking the games own established rules, or suprising the player with new rules and systems. This

\footnotetext{
${ }^{1}$ Tale can be played here: https://ninofrazzitta.itch.io/tale as of 08/10/2021
} 
draws the players attention and can serve to highlight an element of ludnarrative design, a mechanical metaphor, or even serve as a metaphor itself. While ludonarrative is a well established concept in our field, particularly in analysis, in this demonstration we provide an example of its use in practical design and our own approach to its use in movement, puzzles, and defamiliarization.

\section{Tale}

Tale narrates a small adventure of a young boy entering a mysterious world where he finds and frees a young girl belonging to an ancient civilization. The story revolves around the theme of companionship, and the player will explore three fundamental stages of this relationship as they progress with the game.

Firstly the player starts with the discovery of this new relationship focusing on the sense of communication and experimenting with new things. The second part has the two characters separated by an uncontrollable force, exploring loneliness and oppressive anxiety. And finally, the characters are reunited and we explore developing collaboration and growth. Through the duration of the game the player as "the boy" will work with "the girl" as they take their journey through the ancient ruins. The interactions between the two underline that they need each other in order to progress on their journey. This is achieved by having the boy pushing boxes and interacting with leavers, etc. while the girl uses magic powers such as teleporting to progress.

The two characters come from different worlds and have different languages so they cannot communicate properly with each other. The story explores their struggles communicating and how they grow as time passes, showing how their bond becomes stronger. While superficially the story may at first seem to have a "save the princess" premise, this is quickly dispelled with a shift in focus to the collaboration of the two characters. The story finishes the girl completing her journey and taking her place at the ruins summit.

\subsection{Game Design}

Our design makes use of Jesse Schell's lenses of unification [7] helping the design to bring together a cohesive experience that supports a dominant emotion of collaboration. There are three levels in the game, the forest, the underground dungeon, and the sky temple forming a three-act arc in the game, each is designed to support the core emotional themes (communication and experimentation, followed by loneliness and anxiety, followed by collaboration and growth). The level design of those areas is meant to build the right context mirroring the character state of mind - following Zammitto's colour principles[9] that associate colours to certain emotions, and Bura's principles of emotion engineering [2] modifying gameplay using framing devices such as music and visuals to build the appropriate context allowing us to elicit the right emotions in time. In addition to that, we have designed the player's elevation based on the Lopez blockbuster intensity graph[4] allowing us to further regulate the game emotional intensity. 


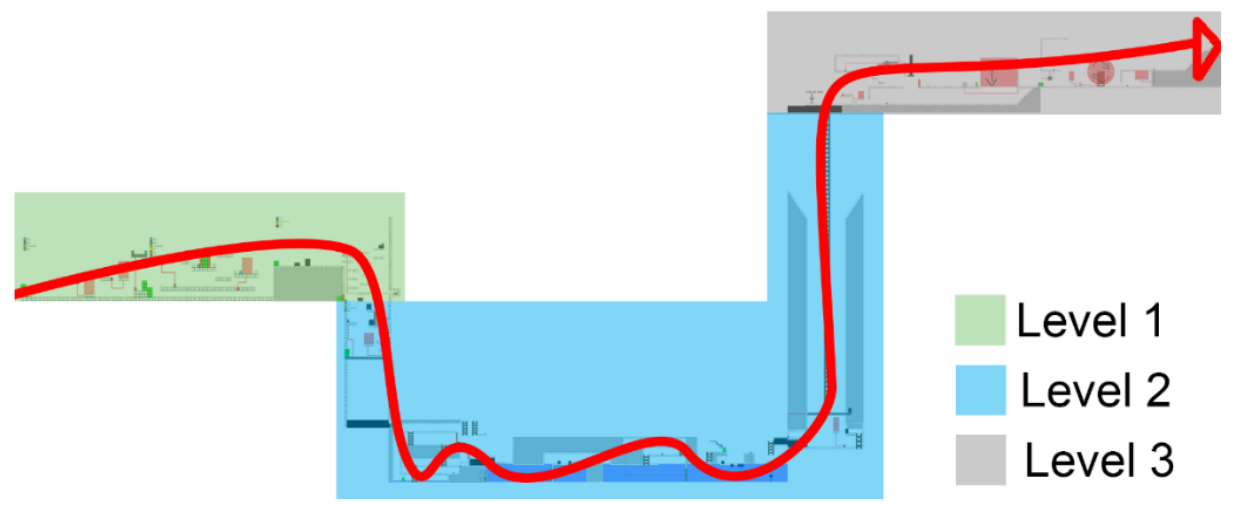

Fig. 1. The structure of Tale's 3 levels

The game presents classic platformer movements and interactions. The player controls "the boy" with standard controls while "the girl" moves either in response to leading and teleportation mechanics, or later moves in response to puzzle context. The game is divided into small areas that contain environmental puzzles. To complete a puzzle both characters must reach the end (which most of the time is signified by a stone portal). For the basic mechanics, the game has "classic" interactions such as pushing boxes, climbing ladders, pulling levers, navigating lifts and moving platforms, and collecting keys. The core mechanic used is the teleportation of "the girl" who can be positioned on platforms or switches to complete the puzzle using initially static teleportation stones, and later moveable teleporter orbs (as depicted in figure 2. Puzzles are solved through careful positioning of both characters in order to collect keys and reach the exit, While the player has fine control over the position of one character movement of the other is more challenging and limited by teleportation and leading mechanics, but becomes more flexible as the game progresses.

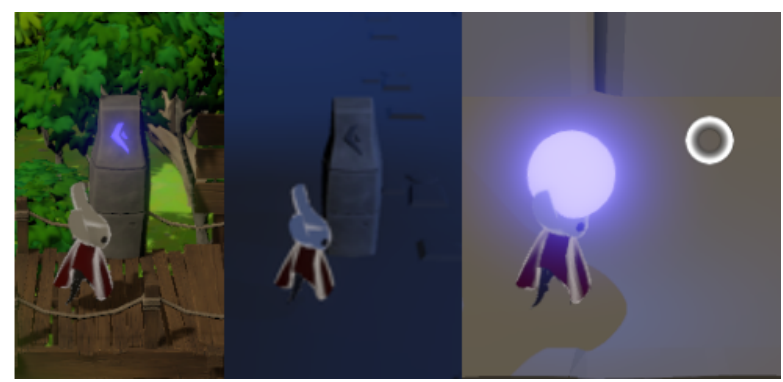

Fig. 2. Movement is key to Tale and teleportation stones and orbs are part of that 


\subsection{Ludonarrative Design}

Mechanics as Metaphor is fundamental to the design of Tale, and are explored through movement within the game some key mechanisms of which are depicted in figure 3 . This begins in a simple manner where, constrained by their inability to verbally communicate, one character may lead the other by the hand. To do this the player must depress a key and keep it held down, maintaining a hold mimicked by the character maintaining physical connection. This gives a sense of closeness and affection defining the relationship between the two characters. These early experiments with movement serve as strong metaphors both for the challenges of communication in an early relationship but also explorations of what is possible together. The design bookends the second level with traversal metaphors in a sudden fall into darkness for the separation, and a long ladder ascent into the reunification of the third level. Our reflective descent and ascent not only evokes Campbell [3] but also serves as a metaphorical movement towards and away from the darker anxiety of this level. The portal mechanic continues to build on the movement metaphor in that the portals require both characters to be together to enter and, as they are reunited on the 3rd level, the portal itself must be put back together by pushing its component parts.

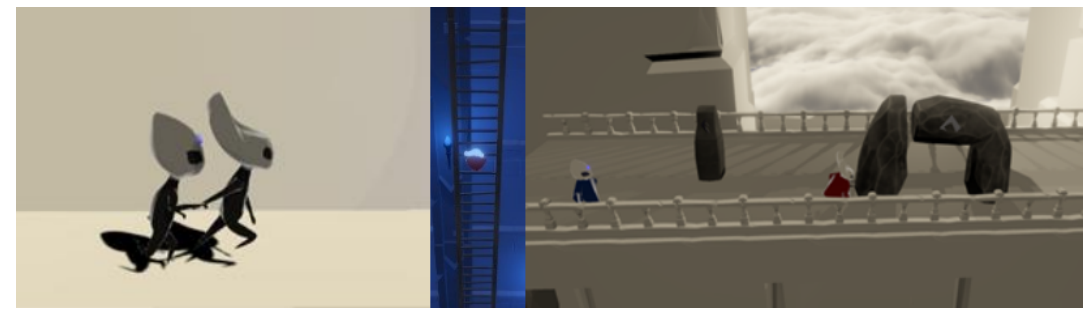

Fig. 3. Movement mechanics: leading, climbing, and bringing the portal together.

We pair this use of mechanical metaphor with defamiliarization. Having completed the first level and explored what is possible between the two characters with teleportation and movement this is then defamiliarized in the second level when the characters are separated, the player is left alone with "the boy" and must solve puzzles, that would be trivial with the teleportation of "the girl", without her. The sudden separation draws the players attention to the absence of a useful mechanic and frequent reminders of the loss in deactivated teleportation stones build the anxiety of the 2nd level. Similarly in the final level as the characters are reunited, while "the girl" and teleportation returns it is now not through static stones that the character will only stand at, but through a moveable and throwable orb that "the girl" will move from on her own accord to trigger interactions in a helpful manner. By subverting the established expectations of teleportation we defamiliarize the mechanic again, drawing the players attention both to the reunification but also that the relationship has grown and the characters are more effective in their collaboration. 


\section{References}

1. Aarseth, E.: A narrative theory of games. In: Proceedings of the International Conference on the Foundations of Digital Games. p. 129-133. FDG '12, Association for Computing Machinery, New York, NY, USA (2012). https://doi.org/10.1145/2282338.2282365

2. Bura, S.: Emotion engineering in videogames: Toward a scientific approach to understanding the appeal of videogames (2008), http://www.stephanebura.com/emotion/

3. Campbell, J.: The hero with a thousand faces, vol. 17. New World Library (2008)

4. Lopez, M.: Gameplay fundamentals revisited: Harnessed pacing \& intensity. Gamasutra $12(2008)$

5. Mitchell, A., Kway, L., Neo, T., Sim, Y.T.: A preliminary categorization of techniques for creating poetic gameplay. Game studies 20(2) (2020)

6. Rohrer, J.: What i was trying to do with passage. Jason Rohrer's webpage (Nov 2007), http://hcsoftware.sourceforge.net/passage/statement.html, accessed $20 / 07 / 2021$

7. Schell, J.: The Art of Game Design: A book of lenses. CRC press (2008)

8. Shklovsky, V.: Art as technique. University of Nebraska Press (1965)

9. Zammitto, V.L.: The expressions of colours. In: DiGRA Proceedings of the 2005 DiGRA International Conference: Changing Views: Worlds in Play (2005) 